for attendance. In addition a questionnaire survey was administered prospectively to 172 rebook patients as regards reasons for re-attendance.

Results In the retrospective study, 106/150 (71\%) were female, the average age of males was 30.4 , the average age of female was 23.9. 56\% (84/150) of patients attended three times or more related to genital warts, genital herpes, pelvic pain, contraception or recurrent bacterial vaginosis. In the prospective survey. $24 \%$ stated that they had re-attended because of genital warts, recurrent genital soreness or pelvic pain. 73/172(42\%) were asymptomatic. Between $48-63 \%$ stated they preferred to attend because of the expertise, friendliness and confidentiality of the clinic.

Discussion/conclusion In one study, 56\% of attendees had attended with recurrent issues not related to recurrent bacterial STIs. Between 48-63\% had attended related to friendliness, expertise and confidentiality of the clinic inferring that quality of care and confidentiality are important factors in reasons for re-attendance.

\section{P103 HOW AND WHY DO WE DO TESTICULAR ULTRASOUNDS? A NATIONAL CLINICAL DEVELOPMENT GROUP SURVEY OF GENITOURINARY MEDICINE CLINICS}

${ }^{1}$ Matthew Phillips*, ${ }^{2}$ Ben Goorney, ${ }^{3}$ Uday Joshi, ${ }^{4}$ Phillip Kell. ${ }^{1}$ Tameside and Glossop Centre for Sexual Health Stockport NHS Foundation Trust, Greater Manchester, UK; ${ }^{2}$ The Goodman Centre Salford Royal Hospitals NHS Foundation Trust, Greater Manchester, UK; ${ }^{3}$ Hull and East Yorkshire NHS Trust, Hull, UK; ${ }^{4}$ South Devon Healthcare NHS Trust, Devon, UK

\subsection{6/sextrans-2015-052126.146}

Background/introduction There is a paucity of guidelines for when testicular ultrasound (USS) should be performed and how easily GUM clinics should be able to access scans.

Aim(s)/objectives To establish what pathways are in place for USS requests and clinical prompts to order a scan.

Methods A 10 question survey was designed using Survey Monkey. This was approved by the BASHH Clinical Development Group, and disseminated within the network via the regional representatives.

Results The link was sent to 139 leads and completed by 111 clinics (79\%). The majority of respondents (92.79\%) had USS located in hospital. $72.97 \%$ services had no guidelines and $48.18 \%$ had no pathway for urgent scans. $77.48 \%$ requested between 1-6/ USS month. No service had to wait $>2$ weeks for urgent requests, with $23.85 \%$ services having same day access. Ranking for symptoms and signs showed 62\% services would often/ always scan for a mass present $>14$ days, and $92.79 \%$ always scan a hard, painless testicular mass.

Discussion/conclusion The majority of services have access to timely USS, although half do not have established pathways for urgent scans. The most concerning clinical features are the persistence of swelling and mass consistency, but for other features, such as pain, respondents felt that further information is required. In general, patients are relying on clinical judgment of experienced clinicians to decide the need for requesting scans. With integration of practitioners with different skills, there is need for a more standardised approach for how, when and why we perform testicular ultrasounds.

\section{P104}

PATIENT STORIES: WHAT CAN WE LEARN FROM LISTENING TO HEALTHCARE WORKERS WITH HIV

Tracey Buckingham*, Larissa Mulka, Eileen Nixon, Daniel Richardson. Brighton and Sussex University Hospitals NHS Trust, Brighton, UK

10.1136/sextrans-2015-052126.147

Background/introduction Issues faced by healthcare-workers (HCW) with HIV are complex. HIV positive individuals continue to experience unacceptable levels of health related stigma. National HIV testing week offers a perfect platform to raise the profile of HIV within our hospital Trust.

Methods HIV positive healthcare workers were approached and asked to write an account of their experiences of testing, living and working with HIV and whether they had chosen to disclose their status to colleagues and the outcome of that experience. Key themes were extracted from the stories.

Results Six healthcare workers living with HIV, on treatment, in care, agreed to share their stories. Key themes from the stories were: missed opportunities for HIV testing pre-diagnosis, misdiagnosis and misunderstanding of HIV from HCW, feeling judged and experiencing prejudice from HCW, loss of professional confidence due to negative attitudes towards HIV/AIDS from HCW, delayed or non-disclosure of HIV status due to experiencing negative comments or behaviours towards HIV in clinical settings: however HCW who disclosed their status at work experienced significant support and empowerment, including a desire to teach and train HCW. Patient stories were used in HIV testing week to promote testing as part of a larger HIV-awareness campaign.

Discussion/conclusion Engaging HIV positive healthcare workers as part of a strategy to increase awareness of HIV in healthcare settings is empowering for patients and a powerful message to colleagues.

\section{P105 SEXUAL HEALTHCARE PROFESSIONALS' ATTITUDES TOWARDS HPV VACCINATION FOR MEN IN THE UNITED KINGDOM}

${ }^{1}$ Tom Nadarzynski*, ${ }^{1}$ Helen Smith, ${ }^{2}$ Daniel Richardson, ${ }^{1}$ Elizabeth Ford, ${ }^{1}$ Carrie Llewellyn. ${ }^{1}$ Brighton and Sussex Medical School, Brighton, UK; ${ }^{2}$ Brighton and Sussex University Hospitals, Brighton, UK

\subsection{6/sextrans-2015-052126.148}

Background/introduction Men who have sex with men (MSM) are at risk of HPV-associated genital warts and cancers but are unlikely to benefit from female-oriented HPV vaccination.

Aim To examine the attitudes of sexual healthcare professionals (SHCPs) towards HPV vaccination of men in the UK.

Methods An e-survey of SHCPs' views was conducted in JulyAugust 2014. Members of UK-based professional sexual health associations were invited to participate by direct email and members' newsletters. Responses to 18 statements, with corresponding Likert scales, were used to examine their views on HPV vaccination.

Results Amongst 325 respondents (46\% Doctors, 26\% Nurses and $15 \%$ Health advisors), $14 \%$ are already vaccinating men against HPV and $83 \%$ would recommend gender-neutral HPV vaccination. While $64 \%$ would also recommend targeting MSM, 